\title{
Produktivitas Cengkih Hutan (Syzygium obtusifolium L.) di Kecamatan Leihitu Kabupaten Maluku Tengah
}

\author{
Productivity of Forest Clove (Syzygium obtusifolium L.) In Leihitu Sub-District, Central Maluku \\ District
}

\section{Herman Rehatta*, Dessy A. Marasabessy, Safril H. Sopalauw}

\author{
Program Studi Agroekoteknologi, Jurusan Budidaya Pertanian, Fakultas Pertanian, Universitas Pattimura \\ Jln. Ir. M. Putuhena Kampus Poka, Ambon 97233 \\ *E-mail Penulis Korespondensi: hermanrehatta@gmail.com
}

\begin{abstract}
Clove trees (Syzygium obtusifolium L.) have a significant role in supporting efforts to increase state revenue. The purpose of this study was to obtain aproductivity data of the forest clove in the Leihitu Sub-district, Central Maluku District, from a case study in Hitu Lama, Hitu Mesing, Mamala, and Morela villages. The research method used was a survey method. The results showed that variations in the yield level in each study location were influenced by the factor of the proportion of immature trees, productive trees, and damaged old trees. The average productivity of forest clove in the study location was $5603.5 \mathrm{~kg} / \mathrm{ha}$ or equivalent to 5.6 tons $/ \mathrm{ha}$.
\end{abstract}

Keywords: forest clove, production, productivity, tree conditions

\section{ABSTRAK}

Tanaman cengkih (Syzygium obtusifolium L.) mempunyai peranan yang cukup besar dalam menunjang upaya peningkatan pendapatan negara. Tujuan penelitian ini adalah untuk mendapatkan data produktivitas cengkih hutan di kecamatan Leihitu Kabupaten Maluku Tengah, dari studi kasus di desa-desa Hitu Lama, Hitu Mesing, Mamala, dan Morela. Metode penelitian menggunakan metode survey. Hasil penelitian menunjukkan adanya variasi tingkat produksi pada masing-masing lokasi penelitian, dipengaruhi oleh faktor proporsi tanaman belum menghasilkan, tanaman menghasilkan, dan tanaman tua rusak. Menunjukkan rata-rata produktivitas cengkih hutan di lokasi penelitian adalah $5603,5 \mathrm{~kg} / \mathrm{ha}$ atau setara dengan 5,6 ton/ha.

Kata Kunci: cengkih hutan, produksi, produktivitas, kondisi tanaman

\section{PENDAHULUAN}

Tanaman cengkih hutan (Syzygium obtusifolium L.) merupakan tanaman rempah asli Maluku, sehingga memiliki potensi dikembangkan karena sesuai dari segi iklim dan tanah. Tanaman rempah ini memiliki nilai ekonomi yang tinggi dan mempunyai banyak manfaat. Pada zaman dahulu banyak penjajah yang datang untuk menjajah Maluku, salah satu faktornya karena Maluku kaya dengan hasil rempah-rempah. Tanaman cengkih dikenal sebagai tanaman rempah yang digunakan sebagai obat tradisional. Produksi cengkih mempunyai peranan yang cukup besar dalam menunjang upaya peningkatan pendapatan negara karena sampai saat ini rokok yang merupakan salah satu sumber pendapatan negara yang terbesar dibanding dengan sumber-sumber pendapatan lainnya. Cengkih juga termasuk salah satu penghasil minyak atsiri (Bustaman, 2011) yang bisa digunakan sebagai bahan baku industri farmasi maupun industri makanan, tetapi penggunaan yang terbanyak sebagai bahan baku rokok (Towaha, 2012).

Cengkih dimanfaatkan karena kandungan eugenolnya sebagai penghasil minyak atsiri. Minyak cengkih dapat diperoleh dari bunga cengkih (clove oil), tangkai bunga (clove steam oil), dan daun cengkih (clove leaf oil) (Hadi, 2012). Minyak cengkih memiliki kandungan bahan lain seperti eugenil metileter, eugenil asetat, senyawa kimia seperti eugenin, asam oleanoat, asam galotamat, fanilin, karyofilin, resin dangom (Thomas, 2017).

Produksi cengkih pada tahun 2015 mencapai 139.641 ton dari luas areal 535.694 dengan produktivitas $441 \mathrm{~kg} / \mathrm{Ha}$, pada tahun 2017 produksi cengkih naik menjadi 140.056 ton dari luas lahan $542.750 \mathrm{Ha}$ dengan produktivitas $425 \mathrm{kh} / \mathrm{Ha}$ (Statistik Perkebunan Indonesia, 2017). Permintaan akan produk cengkih terus meningkat dari waktu ke waktu. Indonesi adalah negara pemasok terbesar cengkeh dunia (80\%). Maluku merupakan daerah penghasil kedua setelah 
Sulawesi Selatan dengan kontribusi produksi $12,48 \%$ dari produksi Nasional (Santoso, 2018). Total luas tanaman cengkih di Maluku mencapai $38.515 \mathrm{Ha}$ dengan daerah penyebaran terbesar di Maluku Tengah, Seram Bagian Timur, Seram Bagian Barat dan Buru Selatan. Produksi cengkih Maluku tahun 2017 mencapai 20.598 ton dengan produktivitas $669 \mathrm{~kg} / \mathrm{Ha}$ dari jumlah petani (KK) 72.714 (BPS, 2017). Varietas cengkih yang banyak dibudidayakan di Indonesia antara lain: zansibar, sikotok, dan siputih (Moningka et al., 2012).

Umumnya, tanaman cengkih hutan di Maluku masih dikelola secara tradisional, potensi cengkih hutan cukup tinggi namun produktivitas cengkih hutan secara umum belum diketahui. Menurut hasil penelitian pendahuluan, ditahui bahwa harga cengkih hutan satu tahun terakhir (2017) pada kisaran harga (Rp. 46.000Rp. $70.000 / \mathrm{kg}$ ). Dengan adanya potensi harga pasar cengkih hutan maka petani tertarik untuk membudidayakan tanaman cengkih hutan ini. Berdasarkan survey awal yang dilakukan, potensi penyebaran cengkih hutan Maluku terdapat di Kecamatan Leihitu di dominasi oleh Desa Hitu Lama, Desa Hitu Mesing, Desa Mamala, dan Desa Morela.

Informasi mengenai potensi dan produksi cengkih hutan masih sangat terbatas serta penelitian tentang cengkih hutan masih belum banyak dilakukan, oleh karena itu perlu dilakukan penelitian tentang "Produktivitas Cengkih Hutan di Kecamatan Leihitu Kabupaten Maluku Tengah". Penelitian ini bertujuan untuk mendapatkan data produktivitas tanaman cengkih hutan di Kecamatan Leihitu Kabupaten Maluku Tengah.

\section{METODOLOGI PENELITIAN}

\section{Tempat dan Waktu Penelitian}

Penelitian ini dilaksanakan di Desa Hitu Lama, Desa Hitu Mesing, Desa Mamala, dan Desa Morela Kecamatan Leihitu Kabupaten Maluku Tengah dan berlangsung pada bulan September sampai dengan November 2018.

\section{Bahan dan Alat Penelitian}

Bahan yang digunakan dalam penelitian ini adalah populasi tanaman cengkih hutan. Alat yang digunakan adalah camera, meter rool, labtop, GPS, Altimeter dan kuisioner.

\section{Metode Penelitian}

Metode yang digunakan dalam penelitian ini adalah metode kualitatif (survey). Pemilihan responden dilakukan secara sengaja (purposive sampling). Informasi mengenai produktivitas tanaman cengkih hutan diperoleh dari pengamatan langsung dan wawancara yang dilakukan terhadap responden di Desa Hitu lama, Desa Hitu Mesing, Desa Mamala dan Desa Morela.

\section{Pelaksanaan Penelitian}

\section{Penentuan Sampel}

Penelitian ini diawali dengan melakukan survei pendahuluan untuk penetapan desa sampel di Kecamatan Leihitu Kabupaten Maluku Tengah. Setelah mendapatkan informasi tentang potensi cengkih hutan kemudian dilakukan pengambilan sampel petani yang mengusahakan tanaman cengkih hutan dilokasi penelitian. Jumlah responden yang digunakan tiap desa adalah $20 \mathrm{KK}$ petani cengkih hutan sehingga jumlah responden keseluruhan adalah $80 \mathrm{KK}$. Wawancara langsung yang dilakukan terhadap petani cengkih hutan berpedoman pada kuisioner yang digunakan.

\section{Pengumpulan Data}

Data yang dikumpulkan berupa data primer dan data sekunder. Data primer berupa wawancara dengan petani cengkih hutan secara terstruktur sesuai dengan kuisioner dan pengamatan langsung (visual) terhadap tanaman cengkih hutan yang diusahakan, sedangkan data sekunder diperoleh dari instansi terkait, berupa data iklim, bahan pustaka atau informasi ilmiah yang relevan dengan penelitian ini.

\section{Variabel Pengamatan}

Variabel yang diamati dalam penelitian ini meliputi 20 responden yang mengusahakan tanaman cengkih hutan di tiap lokasi penelitian meliputi:

1. Fisiografi lahan: luas lahan, ketinggian tempat, dan kemiringan lereng.

2. Kepemilikan lahan dan varietas yang dibudidayakan.

3. Jumlah tanaman belum menghasilkan (TBM), tanaman menghasilkan (TM) dan tanaman tua rusak (TTR).

4. Distibusi umur pohon:

Variasi umur setiap pohon sampel tanaman cengkih hutan yang diusahakan (dalam tahun).

5. Teknik budidaya/manajemen kebun tanaman cengkih.

a. Jarak tanam dan pola tanam

b. Pemeliharaan tanamandan sanitasi kebun

6. Musim Panen dan Pasca Panen.

Mencatat waktu awal dan akhir panen (dalam bulan).

7. Produksi:

Poduksi bunga basah dan bunga kering per pohon (Kg/pohon), serta menghitung produksi dari pohon yang telah menghasilkan bunga basah dan bunga kering per luas lahan $(\mathrm{Kg} / \mathrm{Ha})$.

8. Produktivitas:

$$
\text { Produktivitas }=\frac{\text { Produksi }(\mathrm{kg})}{\text { Luas lahan }(\mathrm{Ha})}
$$

\section{Analisis Data}

Data primer maupun data sekunder yang telah dikumpulkan dianalisis secara kualitatif. 


\section{HASIL DAN PEMBAHASAN}

\section{Hasil}

\section{Keadaan Umum Lokasi Penelitian}

\section{Letak Geografis Kecamatan Leihitu}

Luas wilayah lokasi penelitian adalah $258 \mathrm{~km}^{2}$. Secara astronomis terletak antara garis lintang $03,30^{\circ}$ $03,45^{\circ} \mathrm{LS}$ dan garis bujur $127,45^{\circ}-128,15^{\circ} \mathrm{BT}$ (BPS, 2017). Lokasi penelitian di Kecamatan Leihitu yang memiliki batas-batas wilayah sebelah Timur berbatasan dengan Desa Liang, di Kecamatan Salahutu, sebelah Barat berbatasan dengan Laut Buru, sebelah utara berbatasan dengan Laut Seram, dan sebelah selatan berbatasan dengan Kecamatan Teluk Ambon-Baguala. Kondisi tofografi Kabupaten Maluku Tengah berdasarkan kondisi fisik wilayah di Kecamatan Leihitu terdiri dari dataran rendah sampai dataran tinggi.

\section{Kondisi Iklim}

Kondisi iklim pada lokasi penelitian meliputi curah hujan selama 5 tahun terakhir tercantum pada Tabel 1. Curah hujan berkisar antara 1716 sampai 5433 $\mathrm{mm} /$ tahun. Tanaman cengkih membutuhkan curah hujan yang cukup tinggi berkisar antara 1500-4500 mm/tahun. Cengkih merupakan tanaman tropis yang membutuhkan iklim panas dengan kelembapan yang rendah. Temperatur rata-rata berada pada kisaran $20-25^{\circ} \mathrm{C}$. Kelembaban yang tinggi tidak sesuai bagi proses pembuangan tanaman cengkih, karena dapat mengganggu proses kerja geberalin acid sebagai agen pembentuk bunga (Thangaselvabai et al., 2010).

\section{Fisiografi Lahan}

Hasil penelitian fisiografi lahan yang lahan meliputi luas lahan, ketinggian tempat, dan kemiringan lereng, dapat dilihat pada Tabel 2. Rata-rata luas lahan dari ke empat lokasi penelitian adalah 313.75 ha dengan luas lahan cengkih hutan terbanyak berada pada Desa Hitu Lama 421 ha.

Berdasarkan hasil penelitian petani membudidayakan tanaman cengkih hutan pada ketinggian tempat 0-300 $\mathrm{m} \mathrm{dpl} \mathrm{(Tabel} \mathrm{2).} \mathrm{Kemiringan} \mathrm{lereng} \mathrm{yang}$ digunakan petani untuk membudidayakan tanaman cengkih hutan pada lokasi penelitian rata-rata berkisar antara $9-15 \%$ (Tabel 2).

Tabel 1. Curah hujan (mm) di Pulau Ambon Tahun 2013-2017

\begin{tabular}{lrrrrr}
\hline Tahun & $\mathbf{2 0 1 3}$ & $\mathbf{2 0 1 4}$ & $\mathbf{2 0 1 5}$ & $\mathbf{2 0 1 6}$ & $\mathbf{2 0 1 7}$ \\
\hline Januari & 252.1 & 242 & 160 & 110 & 284 \\
Februari & 194.8 & 171 & 196 & 46 & 152 \\
Maret & 77.6 & 60 & 120 & 84 & 143 \\
April & 166.9 & 154 & 180 & 344 & 129 \\
Mei & 395.1 & 417 & 217 & 101 & 751 \\
Juni & 359.6 & 383 & 560 & 155 & 1430 \\
Juli & 1923.1 & 226 & 114 & 743 & 1046 \\
Agustus & 629 & 498 & 103 & 350 & 452 \\
September & 360 & 117 & 4 & 363 & 501 \\
Oktober & 129 & 129 & 13 & 185 & 180 \\
November & 91 & 31 & 24 & 37 & 189 \\
Desember & 220 & 135 & 25 & 179 & 176 \\
\hline Jumlah & 4798.2 & 2563 & 1716 & 2637 & 5433 \\
\hline
\end{tabular}

Sumber: BMKG Pattimura Laha-Ambon (2018)

Tabel 2. Luas lahan, ketinggian tempat dan kemiringan lereng

\begin{tabular}{|c|c|c|c|c|c|c|c|c|}
\hline \multirow[t]{2}{*}{ Desa } & \multirow[t]{2}{*}{$\begin{array}{c}\text { Luas } \\
\text { Lahan } \\
\text { (Ha) }\end{array}$} & \multicolumn{4}{|c|}{$\begin{array}{c}\text { Ketinggian Tempat } \\
(\text { (m dpl \%) }\end{array}$} & \multicolumn{3}{|c|}{ Kemiringan Lereng (\%) } \\
\hline & & $0-100$ & $>100-300$ & $>300-500$ & $>500$ & $<3-8$ & $9-15$ & $16->30$ \\
\hline Hitu lama & 421 & 80 & 20 & - & - & - & 100 & - \\
\hline Hitu mesing & 260 & 60 & 40 & - & - & 10 & 85 & 5 \\
\hline Mamala & 298 & 55 & 45 & - & - & - & 100 & - \\
\hline Morela & 276 & 90 & 10 & - & - & 5 & 60 & 35 \\
\hline Jumlah & 1255 & - & - & - & - & - & - & - \\
\hline Rata-rata & 313.75 & - & - & - & - & - & - & - \\
\hline
\end{tabular}

Sumber: Data Primer (Diolah, September 2018) 


\section{Kepemilikan Lahan dan Varietas}

Lahan budidaya cengkih hutan adalah lahan milik sendiri yang berasal dari warisan leluhur sehingga mengelolah lahan mereka sesuai dengan keinginan mereka sendiri. Varietas cengkih yang dibudidayakan pada lokasi penelitian yaitu varietas cengkih hutan, cengkih tuni, dan cengkih zansibar (Tabel 3).

Tabel 3. Kepemilikan lahan dan varieta cengkih

\begin{tabular}{lcc}
\hline \multicolumn{1}{c}{ Desa } & $\begin{array}{c}\text { Kepemilikan } \\
\text { Lahan }\end{array}$ & Varietas Cengkih \\
\hline Hitu Lama & milik sendiri & Hutan, Tuni, Zansibar \\
Hitu Mesing & milik sendiri & Hutan, Tuni, Zansibar \\
Mamala & milik sendiri & Hutan, Tuni, Zansibar \\
Morela & milik sendiri & Hutan, Tuni, Zansibar \\
\hline \multicolumn{2}{l}{ Sumber: Data Primer (Diolah, September 2018) }
\end{tabular}

Jumlah Tanaman Belum Menghasilkan, Jumlah Tanaman Menghasilkan, dan Jumlah Tanaman Tua Rusak

Tanaman cengkih hutan yang diusahakan kedaannnya bervariasi menurut umur tanaman. Tanaman belum menghasilkan berumur 1-7 tahun, tanaman menghasilkan 8-40 tahun dan tanaman tua rusak ber umur lebih dari 40 tahun. Berdasarkan hasil penelitian jumlah tanaman cengkih hutan pada ke empat Desa sampel sebanyak 7401 tanaman, meliputi: 3536 tanaman belum menghasilkan (TBM), 3669 tanaman menghasilkan (TM), dan 196 tanaman tua rusak (TTR).

TBM dengan jumlah pohon terbanyak di Desa Hitu Mesing dan terendah di Desa Morela. TM dengan jumlah pohon terbanyak di Desa Morela dan terendah di Desa Mamala, TTR dengan jumlah tanaman terbanyak di Desa Hitu Lama dan terendah di Desa Morela (Tabel 4).

Tabel 4. Jumlah tanaman belum menghasilkan (TBM), jumlah tanaman menghasilkan (TM), dan jumlah tanaman tua rusak (TTR) cengkih hutan

\begin{tabular}{ccccc}
\hline Desa & TBM & TM & TTR & Total \\
\hline Hitu Lama & 1357 & 782 & 71 & 2210 \\
Hitu Mesing & 1502 & 855 & 39 & 2396 \\
Mamala & 373 & 588 & 62 & 1023 \\
Morela & 304 & 1444 & 24 & 1772 \\
\hline Jumlah & 3536 & 3669 & 196 & 7401 \\
\hline Rata-rata & 884 & 917,25 & 49 & 1850,25 \\
\hline
\end{tabular}

Sumber: Data Primer (Diolah, September 2018)

\section{Distribusi Umur Tanaman}

Berdasarkan hasil wawancara dengan petani/responden tentang distribusi umur tanaman cengkih hutan pada keempat lokasi penelitian mulai dari TBM, TM dan TTR dapat dilihat pada Tabel 5.
Tabel 5. Distribusi umur tanaman cengkih hutan di keempat lokasi penelitian

\begin{tabular}{lccc}
\hline \multirow{2}{*}{ Desa } & \multicolumn{3}{c}{ Distribusi Umur Tanaman Cengkih } \\
& \multicolumn{3}{c}{ (Tahun) } \\
\hline HBM & TM & TTR \\
\hline Hitu Lama & $1-6$ & $8-40$ & $>40$ \\
Mamala & $1-7$ & $8-40$ & $>40$ \\
Morela & $1-6$ & $8-40$ & $>40$ \\
Sung & $1-6$ & $8-35$ & $>40$
\end{tabular}

Sumber: Data Primer (Diolah, September 2018). Keterangan: $\mathrm{TBM}=$ Tanaman Belum Menghasilkan; $\mathrm{TM}=$ Tanaman Menghasilkan; TTR = Tanaman Tua Rusak

\section{Teknik Budidaya dan Manajemen Kebun Tanaman Cengkih Hutan}

\section{Jarak Tanaman dan Pola Tanam}

Berdasarkan hasil penelitian sebagian besar petani yang membudidayakan tanaman cengkih hutan menggunakan jarak tanam $5 \mathrm{~m} \times 5 \mathrm{~m}, 6 \mathrm{~m} \times 5 \mathrm{~m}, 6 \mathrm{~m} \times$ $6 \mathrm{~m}$, dan $7 \mathrm{~m} \times 7 \mathrm{~m}$. Pola tanaman yang digunakan adalah dengan monokultur dan polikultur (Tabel 6).

\section{Pemeliharaan Tanaman Cengkih}

Pemeliharaan tanaman cengkih meliputi pemupukan, pemberantasan hama dan penyakit, dan pembersihan gulma (Sanitasi kebun). Berdasarkan hasil penelitian tampak bahwa $100 \%$ dari ke empat lokasi penelitian, petani responden tidak menggunakan pupuk dan pestisida, juga tidak melakukan pengendalian hama. Akan tetapi responden di ke empat lokasi penelitian $100 \%$ membersihkan gulma yang tumbuh disekitar tanaman cengkih (Tabel 7). Tujuan dari membersihkan gulma menurut petani agar dapat mengurangi atau memperkecil persaingan dalam mengambil unsur hara, sehingga tanaman cengkih dapat tumbuh dengan baik. Pembersihan kebun dari gulma dilakukan 1 kali dalam 3 bulan.

\section{Musim Panen dan Pasca Panen}

Panen yang tepat untuk tanaman cengkih hutan ditandai dengan berobahnya warna bunga cengkih dari hijau menjadi hijau kemerahan serta belum mekarnya bunga.

Hasil penelitian dari ke empat lokasi, menunjukkan bahwa petani responden memanen bunga cengkih pada umur 6 bulan. Ciri bunga cengkih siap panen yaitu bunga cengkih mulai berwarna hijau kemerahan. Berdasarkan hasil penelitian dari keempat desa memiliki musim panen yang sama mulai dari bulan pebruari sampai bulan april. Untuk lebih jelasnya dapat dilihat pada Tabel 8. 
Tabel 6. Jarak tanaman dan pola tanam cengkeh hutan di keempat lokasi penelitian

\begin{tabular}{|c|c|c|c|c|c|}
\hline \multirow[t]{2}{*}{ Desa } & \multicolumn{4}{|c|}{ Jarak tanam (\%) } & \multirow[t]{2}{*}{ Pola Tanam } \\
\hline & $5 \times 5$ & $6 \times 5$ & $6 \times 6$ & $7 \times 7$ & \\
\hline Hitu Lama & 20 & 5 & 75 & - & Monokultur, Polikultur \\
\hline Hitu Mesing & 40 & 5 & 45 & 10 & Monokultur, Polikultur \\
\hline Mamala & 20 & 10 & 60 & 10 & Monokultur, Polikultur \\
\hline Morela & 10 & 10 & 60 & 20 & Monokultur, Polikultur \\
\hline
\end{tabular}

Sumber: Data Primer (Diolah, September 2018)

Tabel 7. Tindakan pemeliharaan tanaman cengkih di keempat lokasi penelitian

\begin{tabular}{lccccc}
\hline \multicolumn{1}{c}{ Desa } & \multicolumn{2}{c}{ Penggunaan Pupuk } & \multicolumn{2}{c}{ Pengendalian OPT } & Sanitasi Kebun \\
\hline & Ya $(\%)$ & Tidak $(\%)$ & Hama $(\%)$ & Gulma $(\%)$ & \\
\hline Hitu Lama & - & 100 & - & 100 & 1 kali 3 bulan \\
Hitu Mesing & - & 100 & - & 100 & 1 kali 3 bulan \\
Mamala & - & 100 & - & 100 & 1 kali 3 bulan \\
Morela & - & 100 & - & 100 & 1 kali 3 bulan \\
\hline
\end{tabular}

Sumber: Data Primer (Diolah, September 2018)

Tabel 8. Musim panen cengkih hutan di empat lokasi penelitian

\begin{tabular}{lc}
\hline \multicolumn{1}{c}{ Desa } & $\begin{array}{c}\text { Musim Panen Cengkih Waktu } \\
\text { Awal Panen dan Waktu Akhir } \\
\text { Panen }\end{array}$ \\
\hline Hitu Lama & Pebruari - April \\
Hitu Mesing & Pebruari - April \\
Mamala & Pebruari - April \\
Morela & Pebruari - April \\
\hline Sumber: Data Primer (Diolah, September 2018)
\end{tabular}

Sumber: Data Primer (Diolah, September 2018)

Pengeringan bungan cengkih yang dilakukan oleh petani pada ke empat lokasi penelitian rata-rata menggunakan cara tradisional yaitu dengan menjemur bunga cengkih dibawah sinar matahari langsung. Proses ini dilakukan selama 3-4 hari sampai bunga cengkih benar-benar kering.

\section{Produksi}

Bagian yang diproduksi dan mempunyai nilai ekonomi dari cengkeh hutan adalah buah cengkih yang sering disebut oleh petani bunga cengkih. Dari hasil penelitian mengenai produksi cengkih basah dan kering, yang dinyatakan dalam $\mathrm{kg}$ basah/pohon atau $\mathrm{kg}$ kering/Pohon. Rata-rata produksi basah kg/pohon tahun maupun rata-rata Produksi Kering kg /Pohon tahun dari keempat lokasi penelitian dapat dilihat pada Tabel 9.

Tabel 9. Rata-rata produksi bunga basah dan bunga kering tanaman cengkih hutan per pohon (kg/pohon)

\begin{tabular}{ccc}
\hline \multirow{2}{*}{ Desa } & \multicolumn{2}{c}{ Produksi (kg/pohon) } \\
\cline { 2 - 3 } & Basah & Kering \\
\hline Hitu Lama & 49,85 & 16,95 \\
Hitu Mesing & 64,50 & 23,04 \\
Mamala & 55,1 & 19,68 \\
Morela & 59,5 & 21,25 \\
\hline
\end{tabular}

Sumber: Data Primer (Diolah, September 2018)

\section{Produktivitas Hasil}

Produktivitas cengkih hutan di lokasi penelitian tergolong tinggi (Tabel 10). Produktivitas cengkih hutan tertinggi terdapat pada Desa Hitu Mesing $(6.382 \mathrm{~kg} / \mathrm{ha})$ dan terendah berada pada Desa Hitu Lama (4.695 kg/ha).

Tabel 10. Produktivitas cengkih hutan (kg/ha) di keempat lokasi penelitian

\begin{tabular}{cc}
\hline Desa & Produktivitas \\
\hline Hitu Lama & 4.695 \\
Hitu Mesing & 6.382 \\
Mamala & 5.451 \\
Morela & 5.886 \\
\hline Jumlah & 22.414 \\
\hline Rata-rata & 5603,5 \\
\hline
\end{tabular}

Sumber: Data Primer (Diolah, September 2018)

\section{Pembahasan}

\section{Fisiografi Lahan}

Luas areal usaha cengkih hutan berbeda-beda diantaranya pada Desa Hitu Lama 421 ha, Hitu Mesing 260 ha, Mamala 298 ha dan Morela 276 ha. Variasi luas areal yang dimiliki petani disebabkan karena waktu pembukaan hutan primer yang dilakukan oleh petani hanya sesuai dengan kemampuan petani dengan menggunakan alat seadanya. Pembukaan lahan dilakukan dengan cara menebang pohon dan dibiarkan kering, kemudian dibakar dan dibiarkan begitu saja tanpa pengolahan lanjutan. Semakin meningkat luas lahan semakin besar pula hasil yang diperoleh. Luas dan kepemilikan lahan menentukan tingkat pendapatan petani (Soekarti, 2003). Selain luas lahan, ketinggian tempat juga mempengaruhi produksi cengkih. Sebagian besar petani di keempat lokasi, menanan cengkih hutan pada ketinggian 0-100 m dpl, hanya sebagian kecil petani yang menanam tanaman cengkih hutan pada 
ketinggian >100-300 m dpl. Tanaman cengkih umumnya tumbuh pada ketinggian 200-900 m dpl, dan ketinggian yang paling baik adalah 600-900 m dpl. etinggian tempat $>900 \mathrm{~m}$ dpl cengkih mampu tumbuh tetapi hasilnya kurang baik dan bunganya tidak bagus (Kartasapoerta, 2004).

Pada lokasi penelitian sebagian besar petani membudidayakan tanaman cengkih hutan pada kemiringan lereng $<3-30 \%$. Tingkat kemiringan lereng yang sesuai dengan Good Agriculture Practices (GAP) tanaman cengkih adalah $0-50 \%$ agar jika hujan air tanah dapat tetap stabil (Departemen Pertanian, 2013).

\section{Teknik Budidaya dan Manajemen Kebun Tanaman Cengkih}

Hasil penelitian menunjukkan bahwa teknik budidaya pengelolaan kebun tanaman cengkih di lokasi penelitian masih bersifat tradisional, tidak menggunakan pupuk maupun pestisida. Pengetahuan petani hanya sebatas kebiasaan generasi sebelumnya. Jarak tanam yang digunakan oleh masing-masing petani pada lokasi penelitian bervariasi. Jarak tanam yang digunakan oleh petani dilokasi penelitian umumnya $6 \mathrm{~m} \times 6 \mathrm{~m}$. sedangkan jarak tanam yang baik untuk tanaman cengkih antara lain $7 \mathrm{~m} \times 7 \mathrm{~m}, 7 \mathrm{~m} \times 8 \mathrm{~m}, 8 \mathrm{~m} \times 8 \mathrm{~m}$ diatur secara diagonal (Nurhasanah, 2010; Departemen Pertanian, 2013).

Manajemen pengelolaan dusung cengkih dalam tindakan pemeliharaan tanaman belum sepenuhnya sesuai dengan standar GAP tanaman cengkih diantaranya tidak adanya tindakan pemupukan baik dari awal persiapan lahan seperti pemberian pupuk dasar maupun sampai pemberian pupuk lanjutan. Sesuai dengan prinsip GAP layak secara ekonomi, ramah lingkungan, dan berkelanjutan. Seharusnya petani dapat menerapkan adopsi teknologi seperti pemberian paclobutasol (Moningka et al., 2012) guna menghasilkan tanaman dengan produktivitas dan kualitas hasil tinggi. Pemberian jamur mikoriza arbuskular mampu meningkatkan pertumbuhan benih cengkih dan menurunkan intensitas penyakit bercak daun (Fudhail et al., 2016). Peningkatan produksi cengkih dalam jangka pendek dapat dilakukan dengan memperbaiki struktur tanah dan kondisi tanaman (Fudhail et al., 2016). Rehabilitasi dengan cara mengganti tanaman dengan yang baru memerlukan waktu sedikitnya tujuh tahun agar lahan kembali produktif.

Pemupukan bertujuan untuk meningkatkan produktivitas lahan yang rusak. Pupuk yang dapat diberikan berupa pupuk organik dan pupuk anorganik, atau kombinasi keduanya (Yusdian dan Haris, 2016). Pupuk diberikan setelah tanaman dipanen. Hal ini bertujuan untuk membantu regenerasi pada bagian tanaman yang mengalami kerusakan pada saat panen dan meningkatkan produksi cengkeh setelah panen pada periode selanjutnya (Arinda dan Yantu, 2015; Runtunuwu et al., 2016). Selain upaya tindakan pemupukan dusung cengkih juga kurang mendapat perawatan sehingga pertumbuhannya tidak optimal karena bersaing dengan gulma, terutama dari jenis tanaman semak dan kayu-kayuan selain itu, tanaman cengkih tidak jarang terserang hama dan penyakit. Tanaman cengkih yang hanya dipanen sekali dalam setahun membuat petani tidak bisa mengandalkan komuditas ini sebagai sumber penerimaan sehari-sehari. Oleh karena itu sebagian besar petani berupaya mencari usaha tambahan, terutama sebagai nelayan untuk memperoleh tambahan penghasilan (Pattinama, 2009). Selain itu secara teknis, tanaman cengkih memiliki karakteristik yang khas, yakni panen besar yang diikuti dua kali panen kecil (Simbar, 2014). Hal ini tentu saja mempengaruhi fluktuasi harga cengkih di pasaran dan dapat mempengaruhi motivasi petani dalam melakukan perawatan tanaman (Kingu, 2014)

\section{Tingkat Produktivitas Cengkih Hutan}

Hasil penelitian menunjukkan bahwa rata-rata produktivitas cengkih hutan pada keempat lokasi penelitian adalah 5603,5 kg/ha atau setara dengan 5,6 ton/ha, tingkat produktivitas tertinggi terdapat di Desa Hitu Mesing 6,4 ton/ha dengan rata-rata produksi bunga cengkih kering mencapai 23,04 kg/pohon. Kemudian berturut-turut adalah Desa Morela 5,9 ton/ha dengan rata-rata produksi bunga cengkih kering mencapai 21,25 $\mathrm{kg} /$ pohon, Desa Mamala 5,4 ton/ha dengan rata-rata produksi bunga cengkih kering mencapai 19,68 $\mathrm{kg} /$ pohon dan Desa Hitu Lama 4,7 ton/ha dengan ratarata produksi bunga cengkih kering mencapai 16,95 $\mathrm{kg} /$ pohon. Bila dibandingkan dengan rata-rata produktivitas cengkih nasional yang lebih rendah yang hanya $425 \mathrm{~kg} / \mathrm{ha}$ (Statistik Perkebunan Indonesia, 2017), maka cengkih hutan memiliki potensi untuk dikembangkan, meskipun memiliki kelemahan dalam tingkat harga dan aroma. Bahkan rata-rata produktivitas cengkih Maluku (BPS Maluku, 2017) hanya mencapai $669 \mathrm{~kg} / \mathrm{ha}$. Kendala teknis dalam pengembangan usaha tani cengkih di Maluku adalah proporsi tanaman menghasilkan lebih rendah dibandingan tanaman tua dan tanaman rusak yang jauh lebih besar. Jika hal ini tidak segera di perbaiki, maka pada suatu saat, usaha tanaman cegkih tidak memungkinkan lagi karena proporsi luas tanaman tua atau rusak lebih besar dibandingkan tanaman menghasilkan (Hutuely et al., 2007).

Luas panen menunjukkan kemampuan lahan budidaya memberikan produksi terhadap tanaman yang diusahakan. Luas panen dipengaruhi oleh luas tanaman belum menghasilkan maupun yang telah menghasilkan dan tingkat kerusakan lahan. Luas lahan yang rusak terjadi pada tanaman belum menghasilkan dan tanaman menghasilkan, semakin tinggi tingkat kerusakan lahan semakin rendah luas panen tanaman yang berdampak terhadap rendahnya produktivitas tanaman cengkih (Hutuely et al., 2007).

Kondisi pertanaman dalam suatu areal tanman yang mengalami kerusakan berat perlu mendapat tindakan rehabilitasi. Peremajaan atau rehabilitasi lahan yang rusak membutuhkan waktu minimal 7 tahun untuk menghasilkan tanaman cengkih siap panen. hasil 
penelitian Kementan 2016 dan Hasil penelitian (Santoso, 2018) terdapat hubungan antara peremajaan tanaman dan rehabilitasi lahan dengan produksi tanaman cengkih dimana hubungan tersebut meliputi tingkat kerusakan lahan, luas lahan yang rusak, produksi, harga, luas panen dan jumlah pohon produktif. (Nurmala et al., 2015) jumlah tanaman produktif merupakan salah satu peubah yang berpengaruh nyata terhadap produksi cengkih.

\section{KESIMPULAN}

Kesimpulan dari hasil penelitin ini adalah : 1) Tingkat produktivitas cengkih hutan di Kecamatan Leihitu cukup tinggi sehingga berpotensi untuk pengembangan kedepannya; 2) Produktivitas cengkih hutan pada keempat lokasi penelitian tertinggi terdapat di Desa Hitu Mesing 6,4 ton/ha, kemudian berturut-turut adalah Desa Morela 5,9 Ton/ha, Desa Mamala 5,4 ton/ha, dan Desa Hitu Lama 4,7 ton/ha; dan 3) Variasi tingkat produksi pada masing-masing lokasi penelitian di pengaruhi oleh faktor proporsi tanaman belum menghasilkan, tanaman menghasilkan, dan tanaman tua rusak

\section{DAFTAR PUSTAKA}

Arinda, W., dan M.R. Yantu. 2015. Analisis produksi tanaman cengkeh di Desa Tondo Kecamatan Sirenja Kabupaten Conggala. E-J Agrotekbis 3: 653-660.

[BPS] Badan Pusat Statistik Propinsi Maluku. 2017. Maluku Dalam Angka. CV. Pustikom. Ambon.

Bustaman, S. 2011. Potensi pengembangan minyak daun cengkih sebagai komoditas ekspor Maluku. Jurnal Litbang Pertanian 30: 132-139.

Departemen Pertanian. 2013. Peraturan Menteri Pertanian tentang Sistem Pertanian Organik. Departemen Pertanian. Jakarta.

Fudhail, M., A.K. Paloloang, dan A. Rachman. 2016. Evaluasi kesesuaian lahan untuk pengembangan tanaman Cengkeh (Eugenia aromatica L.) di Desa Marowo dan Bonevoto Kecamatan Ulubongka Kabupaten Tojo Una-Una. e-J Agrotekbis 4: 142-150.

Hutuely, L., J.B. Alfons, A.N. Susanto, M.P. Sirappa, A.J. Rieuwpassa, I. Hidayah, E.D. Waas, dan S. Malawat. 2007. Peta Jalan (Road Map) Pengembangan Komoditas Cengkeh di Seram
Bagian Barat dan Maluku Tengah. Laporan Akhir. Ambon (ID): Balai Pengkajian Teknologi Pertanian Maluku.

Kartasapoerta, A.G. 2004. Klimatologi. Jakarta: PT. Bumi Aksara.

Kingu, J. 2014. Cloves export response to trade liberalization in Tanzania: A cointegration analysis. Journal of Economics and Sustainable Development 5: 99-120.

Moningka, F.F., S.D. Runtunuwu, dan J.M. Paulus. 2012. Respon pertumbuhan tinggi dan produksi tanaman cengkeh (Syzigium aromaticum L.) terhadap pemberian paclobutrazol. Eugenia 18: 118-125.

Nurhasanah, S. 2010. Pemisahan Eugenol dari Minyak Cengkeh dengan Cara Distilasi Fraksinasi. Universitas Padjajaran. Bandung.

Nurmala, M. Antara, dan Hj. Hadayani. 2015. Analisis efisiensi penggunaan input produksi usaha tani cengkeh di Kecamatan Dako Pemean Kabupaten Tolitoli. J. Agroland 22: 226-234.

Pattinama, M.J. 2009. Pengentasan kemiskinan dengan kearifan lokal (Studi kasus di Pulau BuruMaluku dan Surade-Jawa Barat). Makara, Sosial Humaniora 13: 1-12.

Runtunuwu, D. Semuel, R. Mamarimbing, P. Tumewu, dan R.M.N Rengkung. 2016. Pengaruh paclobutrazol terhadap kualitas bunga Cengkeh (Syzygium aromaticum L.). Jurnal Bioslogos 6: 33-41.

Santoso, B.A. 2018. Upaya mempertahankan eksistensi cengkeh di provinsi maluku melalui rehabilitasi dan peningkatan produktivitas. Jurnal Penelitian dan Pengembangan Pertanian 37: 26-32.

Simbar, R. 2014. Struktur biaya panen cengkeh di Desa Kaneyan Kecamatan Tareran Kabupaten Minahasa Selatan. Cocos 5.

Statistik Perkebunan Indonesia. 2017. Cengkeh. Direktorat Jendral Perkebunan Indonesia. Jakarta.

Thomas, A.N.S. 2017. Tanaman Obat Tradisional 2. Penerbit Kanisius, Yogyakarta.

Towaha, J. 2012. Manfaat eugenol cengkeh dalam berbagai industry di Indonesia. Perspektif 11: 79-90.

Yusdian, Y. dan R. Haris. 2016. Respon pertumbuhan bibit cengkeh (Syzigium aromaticum (L.) Merr dan Perry) kultivar Zanzibar akibat pupuk NPK dan pupuk organik cair. Paspalum 4: 59-64. 